\title{
Effect of the projection time frame on the techniques for assessment of energy security performance
}

\author{
Yuri Kononov* \\ * Melentiev Energy Systems Institute, SB RAS, Irkutsk, Russia
}

\begin{abstract}
The paper studies the problem of overall assessment of energy sector development options from the standpoint of meeting energy security requirements. It is shown that as the projection time frame extends further into the future, its economic component gains in importance on a par with integral indicators descriptive of strategic threats to and sustainability of energy systems development. Methodological approaches to assessment of these indicators are proposed.

Keywords: energy security, energy sector, projections, sustainability
\end{abstract}

The methodology behind long-term projections of energy systems development should take into account two essential factors: the exponential growth of uncertainty of future conditions and the diminishing importance of projection results for making priority strategic decisions as the time frame extends into the future. This means that depending on a given time period, the importance of indicators telling of the energy security performance of the country changes and, accordingly, different methods of their numerical evaluation are required.

International practices are those of adopting the methods of energy security assessment that are based on the choice of composition and evaluation of different indicators, assigning different weights to them, and designing composite indexes [1]. An example of such a procedure based on the indicator analysis technique is an overall indicator (index) used by the Global Energy Institute U.S. Chamber of Commerce to characterize the dynamics of U.S. energy security [2]. It incorporates the values of 37 measures in nine categories, with these metrics used to create four sub-indexes (Figure 1).

The World Energy Forum (WEF) adopts another composite index that incorporates 15 indicators to assess the energy security performance of 127 countries annually. On this index, Russia ranks 48th out of 127 countries [3], and it scores 45th out of 125 countries on the Energy Trilemma Index of the International Energy Council [4].

The composition of the indicators used largely depends on the interpretation of the concept of energy security. Over 80 interpretations are proposed in the research published abroad [5]. A conceptual definition of energy security is given by the International Energy Agency: "uninterrupted availability of energy sources at an affordable price" [6].

The economic component in the structure of composite energy security indexes used by different international organizations accounts for about 30 percent (Table 1). In fact, its share is larger as it is present in the resource and environmental components as well.
Table 1. Structure of overall indexes of energy security in approaches to assessment of its current performance: the case of the studies published abroad

\begin{tabular}{|l|l|c|}
\hline $\begin{array}{l}\text { Components of } \\
\text { energy security }\end{array}$ & Some of the key indicators & $\begin{array}{c}\text { Share, } \\
\%\end{array}$ \\
\hline Economic & $\begin{array}{l}\text { Electricity and fuel prices } \\
\text { Energy intensity of the } \\
\text { GDP }\end{array}$ & $20-30$ \\
\hline Geopolitical & $\begin{array}{l}\text { Volatility of global energy } \\
\text { markets } \\
\text { Import dependence }\end{array}$ & $15-25$ \\
\hline $\begin{array}{l}\text { Reliability, } \\
\text { flexibility, } \\
\text { and quality of } \\
\text { energy supply }\end{array}$ & $\begin{array}{l}\text { Energy reserves } \\
\text { Political stability }\end{array}$ & $15-25$ \\
\hline $\begin{array}{l}\text { Environmental } \\
\text { sustainability }\end{array}$ & $\begin{array}{l}\text { CO2 emissions from power } \\
\text { plants } \\
\text { The share of RES and NPPs }\end{array}$ & $20-30$ \\
\hline
\end{tabular}

An analysis of the practices adopted in Russia and abroad for assessment of the current and prospective energy security performance of the country [7] shows that the composition of the indicators used and their weights (significance) remain constant, independent of the considered time period. These and other shortcomings, that are getting all the more pronounced when making long-term projections, can be eliminated with the use of optimization models. The significance of individual indicators can be approximated by the impact on changes in the functional (objective function) of the model of the given level or a higher level.

Systems of optimization and simulation models become indispensable in identifying strategic threats. This comprehensive characteristic of the energy security performance should be defined and generalized at different hierarchical levels. At the same time, the composition and degree of aggregation of employed models should depend on the given time frame (Figure 2).

The main strategic threats to energy security include the threat of long-term shortages of energy carriers and electricity and fuel prices that prove unacceptably high

\footnotetext{
* Corresponding author: kononov@isem.irk.ru
} 
for the economy. Quantitative assessment of these and other strategic threats to energy security calls for solving a number of interrelated problems (Figure 3).

An overall indicator of strategic threats could be used to assess the sustainability of the considered option of the energy sector development.

Of different interpretations of the concept of resilience of energy systems development available, the most suitable, for the purposes of solving the problems of long-term projections, is the following: the ability to preserve the given development path under external and internal impacts or to return to it within an acceptable period of time at an acceptable cost [8].

Obviously, all other things being equal, with the system's sustainability improving, the security of its development also increases. However, its numerical evaluation proves challenging.

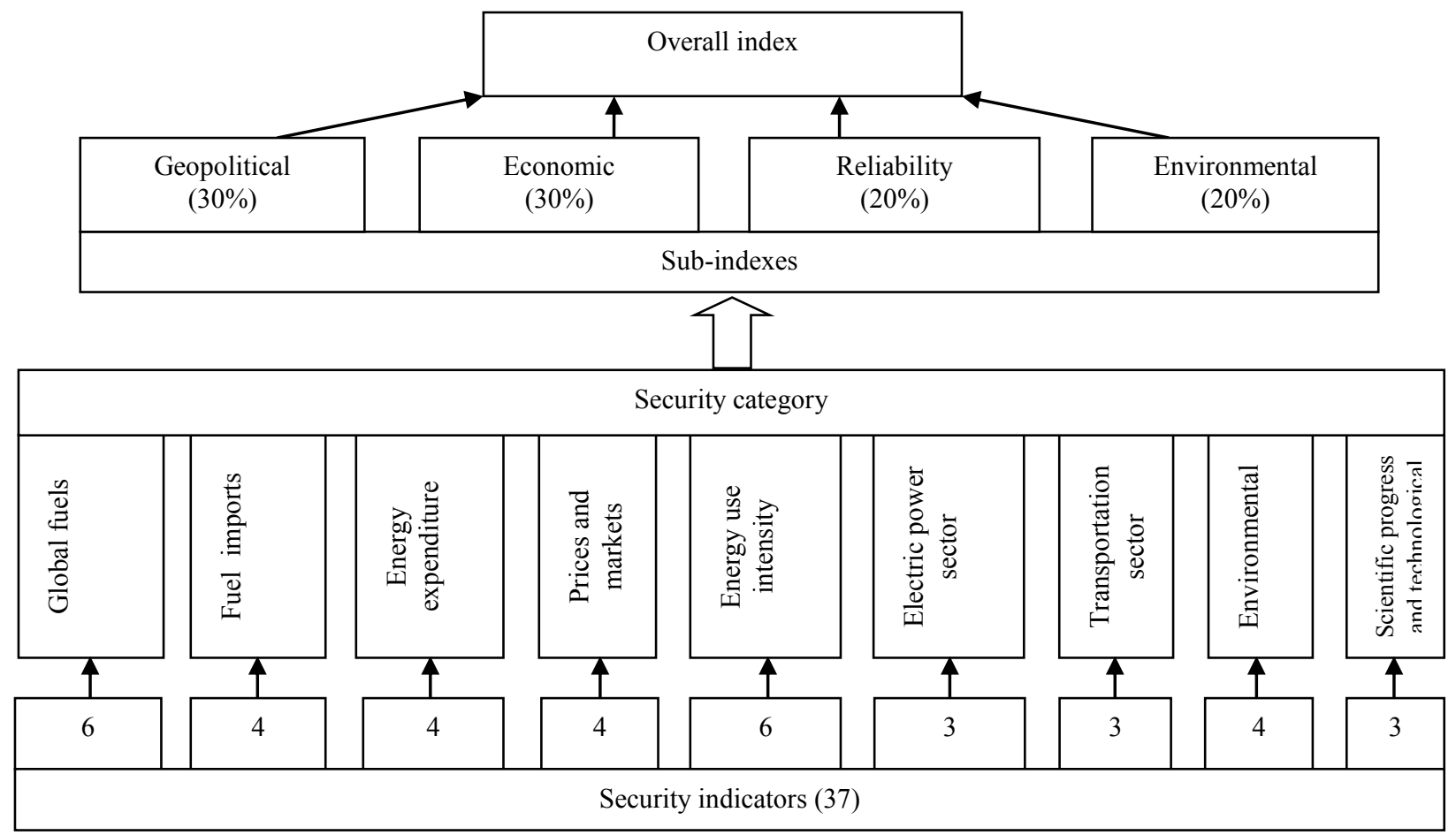

Fig. 1. Construction of the overall index of U.S. energy security risk

The projection time frame of 10 to 15 years or less

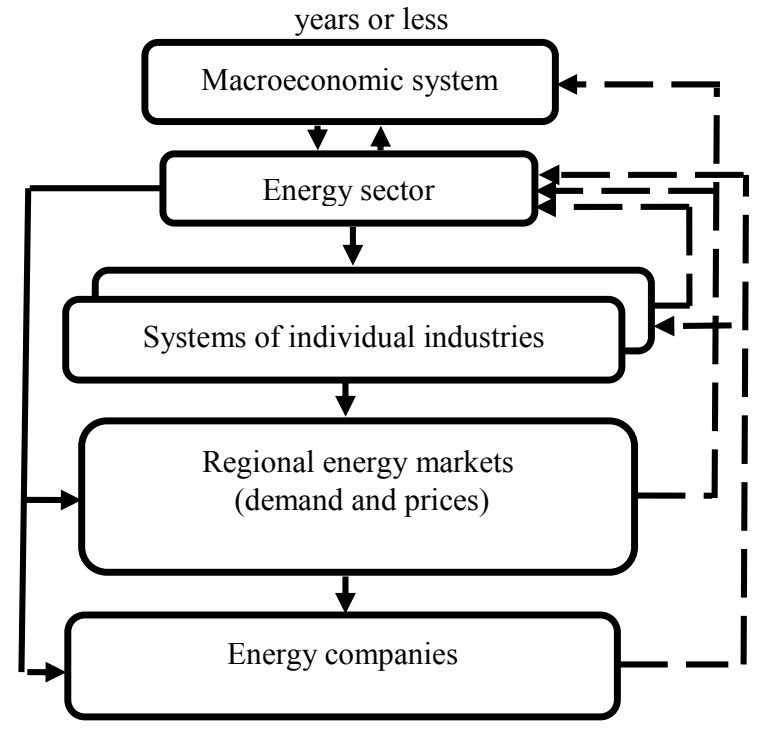

The projection time frame of 15 to 20 years

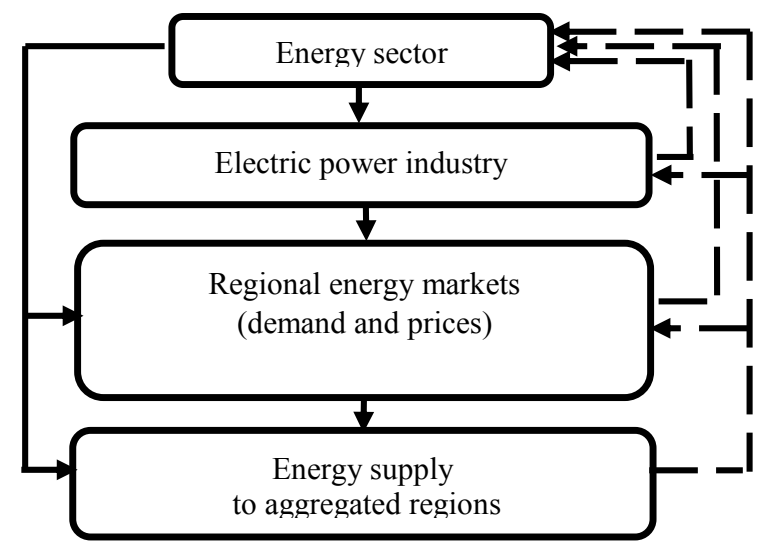

Fig. 2. Reasonable composition of optimization models for overall assessment of the energy security performance at different stages of projection studies of energy sector development 


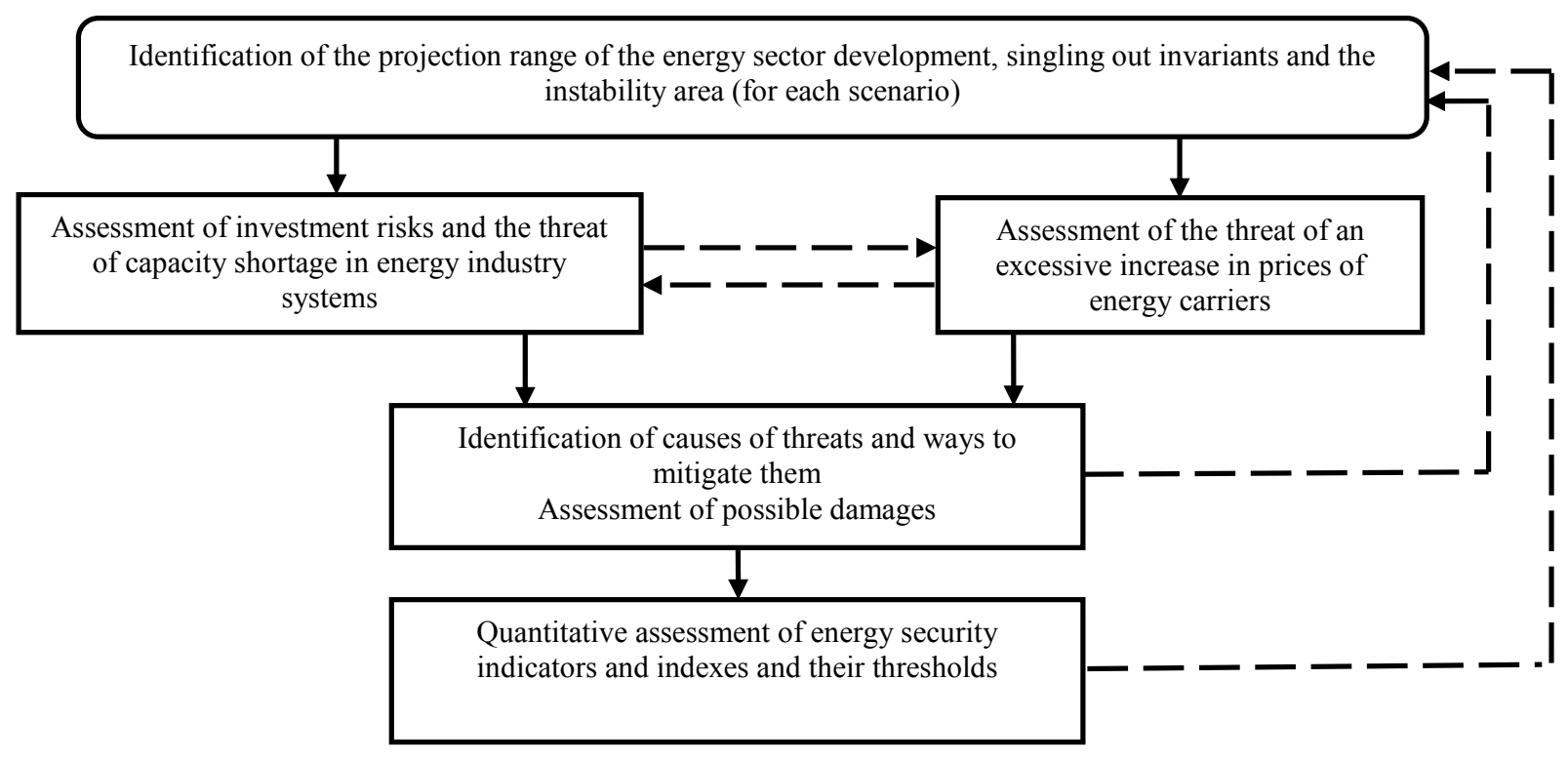

Fig. 3. Problems to be solved in the course of the study and quantitative assessment of the main strategic threats to energy security

In the studies published by the Energy Research Institute of the Russian Academy of Sciences [9], it is proposed to use the deviation of the country's GDP from its value in the reference case as a quantitative measure of Russia's energy sector development sustainability. Such deviation results from a possible realization of scenarios other than the reference one. This approach is suitable for comparative assessment of the options, but it is not clear how to determine the sustainability of the reference option itself.

It appears that it is necessary to distinguish between the relative and actual sustainability of the energy sector development options. The former can be defined by comparing it against the results of the reference case. The assessment of the latter, however, would require summarizing the results of a sustainability analysis of individual industries that make up the energy sector and regional energy supply systems. Overall indicators of strategic threats would also facilitate such an assessment.

In the end, the sustainability of a given option of the system development is determined by the sustainability of dynamics of indicators characterizing the key takeaways of the projection.

An important role in factoring in the uncertainty when making long-term projections of the energy sector development is played by the scenario approach, i.e. modeled calculations under various possible states of the external environment. Based on the analysis of a set of options deemed optimal under certain conditions, the projection range of projected indicators is formed. The sustainability of dynamics of these indicators can be measured by the width of the "uncertainty cone" or by the deviation from one of its boundaries.
The weighted average sustainability value of individual projected indicators allows to assess the sustainability of the reference case or the projected case selected otherwise.

\section{Conclusion}

Numerical evaluation of options for the development of the energy sector and energy supply systems as based on the energy security criterion should become an essential component of projection studies.

The methods for energy security performance assessment depend on the given time frame and the objectives of projection studies.

As the projection time frame extends into the future, the indicators characterizing the economic component of energy security gain in importance.

The indicator analysis technique as applied to energy security performance plays a key role in short-term projections. In projections that go up to 10-15 years into the future, of more importance is the assessment of strategic threats, while in case of long-term projections it is the assessment of the sustainability of development pathways and trends of the country's energy sector.

When constructing overall energy security indexes and evaluating their projected values, a special role is played by contingency calculations that utilize economic and mathematical optimization models.

An important and still unsolved problem of the studies in this field is a numerical evaluation of threshold values of indexes and overall indicators of energy security. These estimates should depend on both the conditions (scenarios) of development of the economy and the energy sector and the projected time frame. 


\section{References}

1. Handbook on Constructing Composite Indicators: methodology and user guide / OECD, 152 p. (2018)

2. Index of U.S. Energy Security Risk (2017 edition) / Global Energy institute U.S. Chamber of Commerce, 89 p. (2017)

3. WEF. Global Energy Architecture Performance Index. Report, $\quad 32$ p. URL: http://www3.weforum.org/docs/WEF Energy Archit ecture Performance Index 2017.pdf (2017)

4. WEC. World Energy Trilemma Index: Monitoring the Resilience of National Energy Systems, 145 p. URL: https://www.worldenergy.org/wpcontent/uploads/2017/11/Energy-Trilemma-Index2017-Report.pdf (2017)

5. B.W. And, WL. Choond/ Energy security: Definitios, dimensions and indexes // Renewable and Sustainable Energy Reviws, № 42, pp. 1077-1093. (2015)

6. IEA. Measuring short-term energy security. $15 \mathrm{p}$. URL:

http://www.yumpu.com/en/document/view/1962105 6/measuring-short-term-energy-security-iea (2001)

7. Kononov Yu.D. Analysis of the experience accumulated abroad in the comprehensive assessment of energy security // Energeticheskaya politika, No. 6, pp. 98-107. (2018) (In Russian)

8. Kononov Yu.D., Kononov D.Yu. Evaluation of sustainability of energy sustems development to energy threats // National Interests: Priorities and Security, vol. 15, iss. 12, pp. 2317-2326. (2019) (In Russian)

9. Lesnykh V.V., Timofeeva T.B. Methodological approach to the assessment of resilience of the energy sector of Russia and its regions // Issues of improving the energy sector. - Saratov. Issue 8: Improving energy systems: Proceedings of the XIII international scientific and engineering conference (Saratov, November 1-3, 2016), pp. 14-17. (2016) (In Russian)

10. Makarov A.A. Approaches to the assessment of resilience and risks of the Russia's energy industry development. In Energy systems analysis: methodology and research findings / Ed. by A.A Makarov and N.I. Voropai. Energy Research Institute of the Russian Academy of Sciences, 309 p. (2018) (In Russian) 